\title{
Health and safety hazards identification and risk assessment in the swimming pools using combined HAZID and ALARP
}

\author{
Mohsen Hesami Arani $^{1,2}{ }^{\circledR}$, Nematollah Jaafarzadeh $^{3}{ }^{\circledR}$, Peyman Khaleghi Dehabadi $^{\circledR}{ }^{\circledR}$ Gholamreza Mostafaii $^{5^{\circledR}}$,

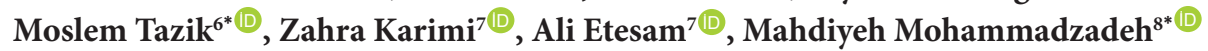 \\ ${ }^{1}$ Student Research Committee, Iran University of Medical Sciences, Tehran, Iran \\ ${ }^{2}$ Research Center for Environmental Health Technology, Iran University of Medical Sciences, Tehran, Iran \\ ${ }^{3}$ Toxicology Research Center, Ahvaz Jundishapur University of Medical Science, Ahvaz, iran \\ ${ }^{4}$ Department of Occupational Health Engineering, Aran and Bidgol Health Center, Kashan University of Medical Sciences, Kashan, \\ Iran \\ ${ }^{5}$ Department of Environmental Health, School of Health, Kashan University of Medical Sciences, Kashan, Iran \\ ${ }^{6}$ Department of Environmental Health Engineering, Tehran University of Medical Sciences, Tehran, Iran \\ ${ }^{7}$ Department of Environmental Health Engineering, Aran and Bidgol Health Center, Kashan University of Medical Sciences, Kashan, \\ Iran \\ ${ }^{8}$ Social Determinants of Health (SDH) Research Center and Department of Environment Health and Kashan University of Medical \\ Sciences, Kashan, Iran
}

\begin{abstract}
Background: Swimming pools are recreation and sport sites where the lack of safety and health can have severe adverse effect on public health. This study aimed to identify and assess health and safety risks using HAZID and ALARP techniques in the different parts of the swimming pools.

Methods: In this applied study, health risks were identified by field observations and environmental health questionnaire consisting swimming pool environmental health checklist, safety of equipment and so on. Then, the risks were categorized and corrective revisions were proposed. Data were analyzed using SPSS version 19.

Results: After data analysis, 41 types of safety hazard and 35 types of health risk (potential and existing) were identified. A total of 7 work units and 6 jobs in swimming pools were classified, and 52 types of health risk and 69 types of safety risk were identified, assessed, and classified. After providing corrective measures, according to the ALARP principle, unacceptable risks were eliminated and 64 risk were classified as acceptable.

Conclusion: According to the results, most of the health risks were related to the swimming pools area. So that health training course for swimmers and increasing health culture have an important role in controlling health risks. Changing the attitude of swimming pools managers and personnel towards health, safety and environment (HSE) issues also have an important role in controlling health and safety risks.

Keywords: Environmental health, HAZID, Swimming pools, Risk assessment, Equipment safety

Citation: Hesami Arani MH, Jaafarzadeh N, Khaleghi Dehabadi P, Mostafaii G, Tazik M, Karimi

$\mathrm{Z}$, et al. Health and safety hazards identification and risk assessment in the swimming pools using combined HAZID and ALARP. Environmental Health Engineering and Management Journal 2020; 7(3): 151-160. doi: 10.34172/EHEM.2020.18.
\end{abstract}

Article History:

Received: 17 April 2020

Accepted: 21 June 2020

ePublished: 14 August 2020

\section{Introduction}

With increasing population growth and the need for physical and mental health and recreation as well as holding various sports at regional, national, and international levels, it is necessary to pay attention to the various dimensions of sports programs, including establishment of appropriate and standard facilities (1). Considering the public interest in water sports, a large number of people attend swimming pools every day at social level and are active in these sport sites. Inappropriate health and safety of swimming pools can be a deterrent to the presence of individuals (2). The simultaneous use of pools by various people is associated with health risks and problems, the most important of which include microbial contamination risk and subsequent diseases (3). In addition, noncompliance with pool safety standards can also result in 
the loss of temporary (fracture, etc.) or permanent (stroke, spinal cord injuries, etc.) physical ability and even death (1). Therefore, identification and elimination of health and safety risk factors can increase the attendance and participation of individuals in these environments, as well as preventing incidents and diseases (2). The need to the safety and health monitoring and controlling of swimming pools is necessary due to the wide range of clients (4). It is thus essential to control pools and match them with health and safety standards (5), which is one of duties of environmental health professionals. Improving the health and safety status of swimming pools along with increasing the attraction and interest in water sports will increase the health and safety status of the community covered. On the other hand, lack of attention to the safety status of sports places has caused accidents to clients and those who are interested in these places. The annual statistics of accidents in Iran's sports places, due to non-observance of safety and health indicators, is an evidence of this claim (6). Also, chemicals used for water purification and disinfection can also create dangers for swimmers or pool workers through skin contact or breathing volatile substances in indoor environments (7). The reaction of chlorine with natural organic matter (NOM) in water can produce disinfection by-products (DBPs) (8). Many studies have shown that DBPs have carcinogenic and noncarcinogenic properties $(9,10)$. Therefore, safety issues are of critical importance in swimming pools. Incidence of accidents can cause disturbances in different levels of society and even be considered as a threat to the society and environment. For this reason, everyone is seeking a safe and low-risk system (11). Safety is a general and universal value that must be maintained and implemented in every culture. To this end, risk and safety management and its strategies should be implemented extensively and comprehensively (12). The word »risk « means uncertainty and indicates the probability of occurrence with a certain severity. The results of risk assessment determine damage inflicted to the system and its subsequent environmental consequences (11). The International Organization for Standardization defined risk as the probability of an incident and its consequences (13). Shafie et al assessed the safety and health status of swimming pools at different times in order to identify the swimming pools weaknesses and hazards (6), because the swimming pool risk assessment-management program ensures that preventive disasters can be prevented and implementation of the risk management plan is one of the essential pillars of the swimmers' safety. Hazard identification is the most important part of any health and safety program, in fact, it is the engine of the system. First, the hazards should be identified to find a way to tackle and eliminate the risk and define the health goals and plans (14). Various studies have investigated the health and safety status of swimming pools from the various safety and health perspectives and reported different results $(15,16)$. Daraei et al reported that pool safety is as important as microbial contamination control of pool water (17). Hon et al also reported that incidents occur in indoor swimming pools more frequently than outdoor ones, so, their safety level should be increased to prevent the occurrence of incidents in such swimming pools (18). Although visits and satiation control are conducted extensively and continuously by environmental health inspectors (19), there are many health and safety complaints about swimming pools (20), therefore, one of the goals of this study was to sensitize health personnel about the health and safety hazards of swimming pools. HAZID technique is one of the techniques by which risk assessment can be carried out at different stages of the system's life. The main objective of this technique is to select safe and affordable design options, and finally, to reduce the cost of damages resulting from possible accidents (21). Various studies have been conducted to identify potential hazards and provide control strategies to reduce risks using HAZID technique $(22,23)$. The aim of this study was to identify and focus on the potential health and safety hazards in swimming pools, and then, assess the risks of these hazards in swimming pools using HAZID technique.

\section{Materials and Methods}

This analytical-observational study was carried out on 7 different units of 3 swimming pools in the north of Isfahan province in 2016, according to the following stages.

\section{Hazard identification}

Hazard identification was carried out using environmental health checklists and HAZID technique. For this purpose, a HAZID hazard assessment team, composed of highly qualified and knowledgeable health, safety and environment (HSE) specialists, should be formed. The team consisted of 3 environmental health experts, one professional health expert, and a pool operator. To identify and evaluate the hazards, the team reviewed and studied all stages of design (24), development and operation of the pools, and paid extensive field visits to different parts of the swimming pools (during the time of operation and repair) (25), so as to match the above-mentioned items to the environmental health guidelines (26). Also, considering the hazards caused by the use of chemicals in the water treatment processes, the hazard identification monitoring was performed and analyzed on a daily and annual basis. Finally, the potential health and safety hazards of the pools were identified by asking questions on human error, health problems, treatment and ventilation processes, devices and equipment performance, inadequate training of personnel, vapors, the absence of control measures leading to hazards, etc during group work sessions using the brainstorming method and HAZID technique, as a hazard identification method. The HAZID technique primarily identifies all the unintended consequences that may occur, as well as the hazards that, if occur, will 


\begin{tabular}{|c|c|c|c|c|c|c|c|c|}
\hline \multicolumn{6}{|c|}{$\begin{array}{l}\text { Unit: } \\
\text { Project Name: }\end{array}$} & \multicolumn{3}{|l|}{$\begin{array}{l}\text { Date: } \\
\text { Assessor: }\end{array}$} \\
\hline No. & Hazard & Cause & Threat & Severity & $\begin{array}{r}\text { Probability } \\
\text { (estimate) }\end{array}$ & Risk Level & Impact & $\begin{array}{l}\text { Control } \\
\text { Strategy } \\
\end{array}$ \\
\hline 1 & & & & & & & & \\
\hline 2 & & & & & & & & \\
\hline 3 & & & & & & & & \\
\hline
\end{tabular}

Figure 1. HAZID worksheet used for hazard identification.

cause such consequences. All reasonably predictable hazards, regardless of their obvious or non-obvious risk, were included in the hazard list. After preparation of the initial list of hazards, their obvious or non-obvious nature was further evaluated (27). The identified hazards were recorded separately for each unit in the HAZID worksheet (Figure 1). It should be noted that these hazards were potentially generated from brainstorming.

\section{Risk assessment}

Risk priority number (RPN) was calculated to prioritize the risks and control measures of each hazard. To calculate $\mathrm{RPN}$, the information required for the probability of errors and the severity of the consequences of hazards were extracted through the list of sanitary complaints of the pools, health visit checklists developed by the environmental health experts, unannounced visits at different times, as well as reviewing technical engineers' point of view. Assessment was carried out using risk indexes (RIs) by HAZID technique (Tables 1 and 2). According to the above-mentioned information, the severity and probability of occurrence of each hazard were selected and recorded in the risk identification sheet (Tables 1 and 2; Figure 1). The RI value was calculated for each of the identified risks by multiplying the probability

Table 1. Ranking of hazard probability $(28,29)$

\begin{tabular}{lll}
\hline Rating & The Probability of Hazard Occurrence & \\
\hline 5 & $\begin{array}{l}\text { Very high: Frequent: Hazard is almost } \\
\text { inevitable }\end{array}$ & Once a month \\
4 & High: Repeated hazard & Six months \\
3 & Moderate: Occasional & Once a year \\
2 & Low: Relatively low probability & Every few years \\
1 & Very low: Extremely unlikely hazard & Once every 10 years
\end{tabular}

of risk and the severity of the consequences. Severity index was scored based on the resulting consequence and the amount of damage inflicted to the system. The increase probability index was also scored considering the likelihood of any risk in the system. RI is calculated as an indicator for classification of risks and provision of corrective and preventive measures.

Risks were classified into three acceptable, moderate, and unacceptable levels. The lowest acceptable risk level is reasonably achievable (30), then, the data were entered into SPSS version 19.

HAZID risk assessment matrix (Table 3) was used to investigate and assess the severity and probability of health, safety, and environmental hazards, as well as threats that could damage capitals (24). Then, the ALARP principle was used to determine the risk assessment index. An intolerable zone is shown in red color (RI>10). The hazards in this zone are unacceptable and require appropriate corrective measures such as design changes and increasing safety of the system, establishment of inspection, repair, and maintenance procedures to reduce the risk level. The negligible zone is shown in blue color $(\mathrm{RI}<3)$. Every hazard is widely accepted in this zone and no further safety measures are needed to reduce the risk (31). The ALARP zone, which is presented as a yellow zone, is located between intolerable and negligible zones. Hazards have acceptable risk levels in this zone, but require further corrective measures to increase the health and safety level of the system based on the ALARP principle $(30,31)$.

- Intolerable region: Risk index $\geq 10$

- ALARP region: $3<$ Risk index $<10$

- Negligible region: Risk index $\leq 3$ (23).

Control measures

After identifying and assessing the risk of health hazards

Table 2. Ranking of hazard severity $(30,31)$

\begin{tabular}{lll}
\hline Rating & The Severity of Hazard Occurrence \\
\hline 5 & E & Catastrophic, death or loss one of the main functions of the body \\
4 & D & Critical (causes the loss of primary function, loss of all safety margins, severe damage, and severe injuries) \\
3 & C & Minor, low damage, light injuries \\
2 & B & Very minor, no injuries, only results in a maintenance action (only noticed by discriminating customers) \\
1 & A & No relevant effect on reliability or safety \\
\hline
\end{tabular}


Table 3. Risk assessment matrix $(24,31)$

\begin{tabular}{|c|c|c|c|c|c|c|c|}
\hline \multirow{2}{*}{ Severity } & \multicolumn{2}{|c|}{ Consequence } & \multicolumn{5}{|c|}{ Increasing Probability } \\
\hline & Safety & Environment & & & C & & E \\
\hline 0 & \multicolumn{2}{|c|}{$\begin{array}{l}\text { Minor effect or health damage, minor losses, negligible } \\
\text { effect, negligible impact }\end{array}$} & $\begin{array}{l}\text { Not } \\
\text { Reported }\end{array}$ & $\begin{array}{l}\text { Occurrence was } \\
\text { reported }\end{array}$ & $\begin{array}{l}\text { Non-health effect, } \\
\text { Non-damage }\end{array}$ & $\begin{array}{l}\text { Every few } \\
\text { years }\end{array}$ & $\begin{array}{l}\text { Many times } \\
\text { in a year }\end{array}$ \\
\hline 1 & \multicolumn{2}{|c|}{$\begin{array}{l}\text { Minor health damage, limited impact, minor damage, } \\
\text { minor impact }\end{array}$} & 1 & 2 & 3 & 4 & 5 \\
\hline 2 & \multicolumn{2}{|c|}{$\begin{array}{l}\text { Major health effect or injury, significant impact, } \\
\text { regional losses, with local effect }\end{array}$} & 2 & 4 & 6 & 8 & 10 \\
\hline 3 & \multicolumn{2}{|c|}{ Death, severe damage, severe effect, national impact } & 3 & 6 & 9 & 12 & 15 \\
\hline 4 & \multicolumn{2}{|c|}{$\begin{array}{l}\text { Multiple deaths, international impact, very severe } \\
\text { losses, very severe effect }\end{array}$} & 4 & 8 & 12 & 16 & 20 \\
\hline 5 & \multicolumn{2}{|c|}{ Non-health effect, non-damage } & 5 & 10 & 15 & 20 & 25 \\
\hline
\end{tabular}

using HAZID technique and determining the risk assessment index using the ALARP principle, consultation sessions were conducted in the presence of environmental health experts and technical experts of the pools to provide control plans in the case of intolerable risks with $\mathrm{RI}>10$ (red zone) and acceptable risks with $3<\mathrm{RI}<10$ (ALARP, yellow). The risk assessment was carried out again after the implementation of health and safety corrective measures.

\section{Results}

While identifying the health and safety hazards associated with swimming pools, 41 types of safety hazards and 35 types of potential and existing health hazards were identified (Table 4) and possible consequences and corrective actions were presented and evaluated by the HAZID team members to reduce the level of system hazards. In a total of 7 work units and 6 occupational categories of the pool, 52 types of health risks and 69 types of safety risk were identified, evaluated, and classified (Figure 2). After the hazard identification, the risk of identified hazards was assessed. The highest and lowest percentages of health hazards were related to the pool and sauna unit, respectively. The highest and lowest percentages of safety risks were related to Unit repair according to Unit repair according to Figure 2, respectively. Then, control measures were implemented for intolerable risks with $\mathrm{RI}>10$ and acceptable risks based on the ALARP principle (Figure 3).

The main categories of control methods include removing or limiting hazards, shielding, installing warning signs, instructions, and training on personal protective equipment. Corrective measures include shielding (on the ceiling), replacement of tools and equipment, installing automatic $\mathrm{PH}$ and chlorine control devices, using personal protective equipment, limiting hazards by installing more ventilation devices on the pool surface, installing warning signs, installing hygiene educational banners, providing guidelines for the utilization of installations, and staff training. Then, risk assessment was carried out again and the results showed a reduction in the RI before and after the implementation of corrective measures in different units (Table 5). The results of comparative evaluation of the RI levels before and after control measures in different parts of the pool showed that the highest RI

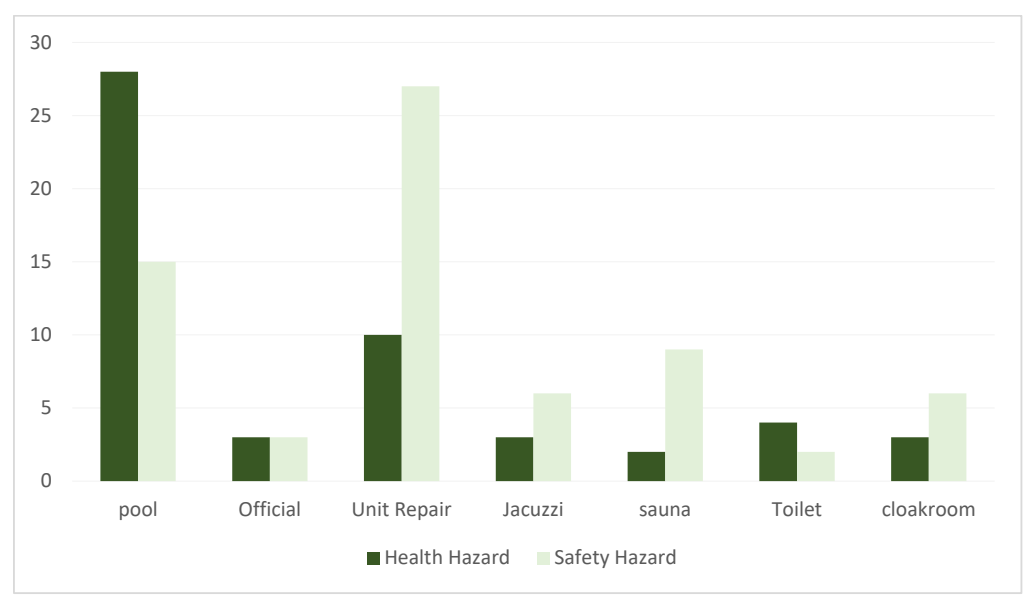

Figure 2. Frequency of safety and health hazards. 
Table 4. HSE hazards identified in the pool $(25,32)$

\begin{tabular}{|c|c|c|c|}
\hline No. & $\begin{array}{l}\text { Location of } \\
\text { Assessment }\end{array}$ & Safety Hazards & Health Hazards \\
\hline 1 & Pool & $\begin{array}{l}\text { Sliding, Drowning, Falling, Inappropriate jokes, Ceiling panel crash, } \\
\text { Channel grating fracture, Insufficient warning signs, Improper } \\
\text { ventilation of the facility, Working at height, Lack of emergency } \\
\text { lighting, Head hit on the edge of the pool, Sliding ladder, Sliding } \\
\text { pool floor, Fracture of ceramic floor, Unstable platforms, Damage } \\
\text { to jumping platforms, Low pool floor lighting, Light bulb falling (18 } \\
\text { types) }\end{array}$ & $\begin{array}{l}\text { Inappropriate washing of the body, Non-removal of } \\
\text { cosmetics before entering the pool, the presence } \\
\text { of the presence of extra people in the pool Urinary } \\
\text { infections, Skin infections, Increased chlorine uptake, } \\
\text { high water temperature, High ambient temperature, } \\
\text { Lack of ventilation, Inappropriate pH, High turbidity, } \\
\text { High temperature of the facility, Heat stress, Noise in } \\
\text { the pool environment, Entering the pool with sneakers, } \\
\text { Using contaminated equipment while swimming, } \\
\text { overcrowding in pool (disregarding pool capacity), } \\
\text { bringing food into the pool, High chlorine gas in pool } \\
\text { air, Unskilled lifeguards, Improper waste management, } \\
\text { Improper cleaning, Improper disinfection of shoes, Use } \\
\text { of protective equipment (belt, armband), Continuous } \\
\text { contact of lifeguards and pool workers with chlorine } \\
\text { gas, Vomiting in the water of pool, Urinary infections } \\
\text { (27 types) }\end{array}$ \\
\hline
\end{tabular}

\begin{tabular}{|c|c|c|c|}
\hline 2 & Official & Lack of emergency lighting, Ergonomic risk, Electric shock (3 types) & $\begin{array}{l}\text { Heat stress, Poor posture, Looking at monitor } \\
\text { constantly ( } 3 \text { types) }\end{array}$ \\
\hline 3 & Sauna & $\begin{array}{l}\text { Acidification of water, Insufficient warning signs, Improper } \\
\text { ventilation of the facility, Floor fracture, Floor bench, High } \\
\text { temperature, Doorknob impairment, Absence of alarm, Lack of } \\
\text { emergency lighting ( } 9 \text { types) }\end{array}$ & High ambient temperature, Inappropriate $\mathrm{pH}$ (2 types) \\
\hline 4 & Cloakroom & $\begin{array}{l}\text { Sliding floor, Inappropriate jokes, Thump, Light bulb falling, Theft, } \\
\text { Wardrobe falling ( } 6 \text { types) }\end{array}$ & $\begin{array}{l}\text { Inadequate disinfection, Improper waste management, } \\
\text { Improper cleaning ( } 3 \text { types) }\end{array}$ \\
\hline 5 & Jacuzzi & $\begin{array}{l}\text { Insufficient warning signs, Sliding floor, High water temperature, } \\
\text { Inappropriate jokes, Absence of handrail ( } 5 \text { types) }\end{array}$ & $\begin{array}{l}\text { Presence of extra people in the Jacuzzi, High } \\
\text { temperature of Jacuzzi water, Urinary infections ( } 3 \\
\text { types) }\end{array}$ \\
\hline 6 & Repair Unit & $\begin{array}{l}\text { Electricity, Falling into the effluent channel, Collision of water jet } \\
\text { hose with face, Improper ventilation of the facility, Chemical barrel } \\
\text { handling, Release of liquid chlorine in the environment, Exposure to } \\
\text { non-standard sound of pump, Working at height, Fire, Lack of safety } \\
\text { data sheet (SDS), Improper layout of equipment, Working with } \\
\text { chemicals, Improper protection of equipment, Unsafe stairs of the } \\
\text { facility, Welding process, Fall from height during service and general } \\
\text { repairs, Falling on the person while replacing the cooling pipe, } \\
\text { Electric shock during repairs, Chlorine inhalation while charging } \\
\text { sodium hypochlorite solution, Crash the sand filter door on the } \\
\text { limbs, Drop of chemical barrels while moving, Improper function of } \\
\text { pool filtration, Lack of emergency lighting, Unprotected electrical } \\
\text { circuits, Unsafe use of emergency lighting system, Unsafe stairs ( } 26 \\
\text { types) }\end{array}$ & $\begin{array}{l}\text { Noise in the pool environment, Improper lighting, } \\
\text { Insect bites, Use of unapproved chemicals, Low or } \\
\text { high residual chlorine, Improper washing of sandwich } \\
\text { filters-Loss of continuous operation of pool filtration } \\
\text { equipment, Improper disinfection of equipment, } \\
\text { Vibration of installations, Improper cleaning (10 types) }\end{array}$ \\
\hline 7 & Toilet & Sliding, Improper ventilation ( 2 types) & $\begin{array}{l}\text { Improper cleaning, Imperfect disinfection, Water } \\
\text { leakage, Impaired flash tank (4 types) }\end{array}$ \\
\hline
\end{tabular}

level was related to the pool area and installations and the lowest one was related to health services. Before the implementation of corrective measures, the RI ranged 4 to 20, but after the implementation of corrective measures and health modifications follow-up, it was reduced to 2-9. Risk assessment data were then entered into SPSS version 19. Descriptive statistical tests (paired $t$ test and Wilcoxon test) were used to compare the primary and secondary risk assessment scores. Statistical significant level was considered at $P<0.05$. The results of comparison of the mean and standard deviation of RI before and after corrective measures showed a reduction in the secondary $\mathrm{RI}$, indicating the effectiveness of corrective measures (Table 6).

According to the ALARP principle, unacceptable risks were eliminated and 64 risks were classified as acceptable (Figure 3).

The results of evaluation and analysis of identified hazards showed that inappropriate ventilation of the pool environment accounted for the highest percentage of health 


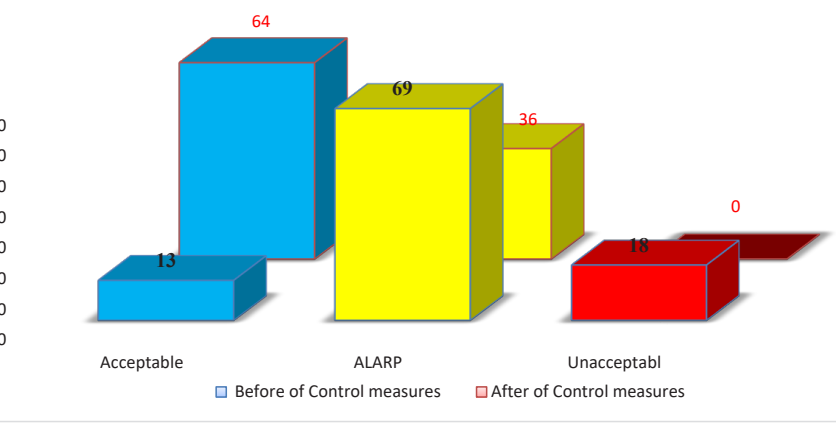

Figure 3. Frequency of risk index (RI) before and after control measures.

risks. With regard to the classification of health risks, the highest risk score was obtained for combined chlorine and inappropriate ventilation, acidification of water during swimming activity, and high ambient temperatures, which received RPN of 20 in the risk matrix. Slippery surfaces accounted for the highest percentage of safety hazards. With regard to the classification of health risks, the highest risk score was related to chemicals, inhalation of chlorine during charging, and electric shock during repairs, which ranked $3 \mathrm{E}$ and $4 \mathrm{D}$ in the risk matrix. The results of data analysis showed a significant relationship between the high chlorine concentration and chlorine gas odor in the environment. There was also a significant relationship between the health risks of inappropriate washing of the body and non-removal of cosmetics before entering the pool with high combined chlorine. In order to determine the effect of intervention, the marginal homogeneity test was used. This test simultaneously examines the equality of marginal percentages before and after intervention, and shows the pre- and post-intervention marginal distributions are significantly different.

\section{Discussion}

There is a chain of chemical and mechanical processes in swimming pools that, if not controlled, can lead to adverse effects of HSE for swimmers and pool personnel. Therefore, the existence of any defects, directly or indirectly, leads to the actualization of the hidden risks (33). Therefore, the present study conducted on the establishment of an HSE in swimming pools can improve the health status of the community covered. One of the effective and efficient risk assessment and management techniques is HAZID technique, which is used to identify hazards and assess risks at different stages in order to

Table 5. Comparison of risk indicators in different units before and after control measures

\begin{tabular}{|c|c|c|c|c|c|}
\hline \multirow{2}{*}{ No. } & \multirow{2}{*}{ Location of Assessment } & \multicolumn{2}{|c|}{ Minimum Risk Index } & \multicolumn{2}{|c|}{ Maximum Risk Index } \\
\hline & & Before & After & Before & After \\
\hline 1 & Pool & 8 & 4 & 20 & 8 \\
\hline 2 & Official & 6 & 2 & 9 & 3 \\
\hline 3 & Sauna & 8 & 4 & 12 & 6 \\
\hline 4 & Cloakroom & 3 & 2 & 12 & 9 \\
\hline 5 & Jacuzzi & 6 & 3 & 15 & 9 \\
\hline 6 & Repair Unit & 9 & 3 & 20 & 8 \\
\hline 7 & Toilet & 4 & 2 & 9 & 3 \\
\hline
\end{tabular}

Table 6. Mean and standard deviation of risk index (before and after control measures) based on the work unit

\begin{tabular}{cccc}
\hline \multirow{2}{*}{ No. } & Location of Assessment & Primary Risk Index $\left(\mathbf{R I}_{\mathbf{1}}\right)$ & Secondary Risk Index $\left.(\mathbf{R I})_{2}\right)$ \\
\cline { 3 - 4 } & & Mean \pm Standard Deviation & Mean \pm Standard Deviation \\
2 & Pool & $11.7 \pm 2.91$ & $6.20 \pm 1.42$ \\
3 & Official & $5.3 \pm 2.21$ & $2.71 \pm 1.12$ \\
4 & Sauna & $7.9 \pm 2.46$ & $3.29 \pm 1.32$ \\
5 & Cloakroom & $6.11 \pm 2.21$ & $3.1 \pm 1.19$ \\
6 & Jacuzzi & $9.42 \pm 2.52$ & $3.98 \pm 1.61$ \\
7 & Repair Unit & $12.58 \pm 3.41$ & $6.65 \pm 1.82$ \\
\hline
\end{tabular}


provide appropriate control measures. In fact, this method examines the existing and potential risks and threats in two general and partial methods. The main objective of this technique is to enhance the effectiveness of elimination or control measures for potential hazards in stages of predesign, design, construction, installation, maintenance, testing, and inspection of equipment, cost-effectiveness, and time-consuming, and eventually, reducing incidents and possible costs (34). To this end, it is logical to use the HAZID technique to exactly identify the pool-derived HSE hazards because this method identifies the smallest to the biggest risks of the system exactly to the HSE experts through identifying the existing and potential hazards and threats so that they take precise control strategies after achieving a complete and comprehensive understanding of the current conditions (35-37). The results of evaluation of the severity and probability of risks before and after the implementation of corrective measures showed that such measures had a significant effect on the reduction of risk probability, so that it resulted in the reduction of the secondary RI, which is consistent with the results of the study of McCoy et al, who reported a significant difference in the average risk probability before and after the corrective measure (38).

The most important swimming pools-related health hazards include high concentration of combined chlorine and increased chlorine odor in the environment and inappropriate ventilation of the pool environment, which is consistent with the results of the studies by Nikaeen et al on swimming pools in Isfahan, and Ghaneian et al on swimming pools in Yazd $(41,42)$. Ghaneian et al reported that controlling the proper function of the purification and chlorination system, observation of the swimmerpool area ratio, individual hygiene, and taking a shower before entering the pool are among the most important factors affecting the reduction of microbial quality of swimming pool water in Yazd (43). Therefore, the development of health measures to prevent common and water-borne diseases is one of the most important factors directly affecting the treatment of swimming pool water and health status of swimmers (44). $\mathrm{PH}$ control is very important in terms of sanitation because it is essential for the proper control of the effectiveness of the disinfectant (45). In a previous research in the United States, Roy found that the microbial contamination rate of the water can be determined with $95 \%$ confidence by measuring $\mathrm{PH}$ level, free chlorine residual, and the number of swimmers in the pool (46), therefore, one of effective and efficient measures to reduce the risk score of these health hazards is to train swimmers on health issues and health control measures. The results of the present study and the reduction of the secondary RI after the implementation of educational strategies and increasing health culture of swimmers indicate the effectiveness of education in eliminating health hazards such as high $\mathrm{PH}$ in sauna, water turbidity, and combined chlorine in the swimming pool, suggesting that there is a significant relationship between standardization of the acceptable levels of combined chlorine in pools and $\mathrm{PH}$ of sauna with individual health education before entering the pool. It should be noted that the institutionalization of this important part of the HSE management system depends on the management and pool personnel and their attitude towards safety issues. The statistical analysis of the data using Kruskal-Wallis test showed a direct statistical relationship between chlorine odor dispersion in the pool area and elevated combined chlorine $(P=0.001)$, which could be due to excessive number of swimmers and non-appropriate washing of body before entering the pool. One of the critical safety hazards is the high water temperature, which, if at risk swimmers are not informed before entering the pool, it could be associated with death, and such consequence was found after reviewing the existing records. In addition to assessing the current status of the swimming pool water in the present study, the relevant existing statistics were also analyzed and water temperature level was reported higher than the permissible level in most cases, which is consistent with the results of the study of Ghaneian et al, indicating that the water temperature was exceeded the permitted level in $87 \%$ of the cases (47). The results of statistical analysis of the corrective measures presented in the present study and comparative evaluation of the reduction of the secondary RI resulting from the implementation of these measures showed a significant relationship RI and corrective measures $(P=0.001)$, which indicates the high effectiveness of corrective measures for improper performance (48). Control of the pool water treatment system, observing swimmers-pool area ratio, observing personal hygiene, and taking a shower before entering the pool reduced the secondary RI, which have been clearly recognized in numerous studies, as the most important factors affecting the increase of health risks and microbial contamination of swimming pools water. This finding is consistent with the results of a study by Jouzi et al, who reported training workers and swimmers and raising their level of awareness on hazards as a proper and effective method to control risky resources, which in turn can reduce the level of risk of units by training operators (48).

\section{Conclusion}

Despite health inspections, safety hazards identification in swimming pools is a neglected part of the research that was comprehensively studied in the present study. According to the results of the present study, HAZID is a compatible method for identifying and assessing the risk in the swimming pools. Consistent with the results of some similar studies $(49,50)$, it was revealed that paying attention to the safety issues of swimming pools is also as important as the microbial contamination of water, and the Ministry of Health as health administrators, should explain the standards and safety indicators of swimming 
pools as well as indicators of the microbial contamination of water and bridge the regulatory and educational gap caused by the lack of these standards (17). Therefore, evaluation of the safety risks and their causes is the most effective strategy to reduce the risk score of safety hazards for the promotion of equipment safety in the first stage and providing safety training and instructions. based on the results of this study, some corrective measures such as: continuous monitoring and risk assessment, holding safety training courses for employees, provide ergonomic tables and chairs, check the safety of cables and electrical equipment, secure the facilities and install appropriate ventilation, swimmers' health education and install appropriate safety and health warning signs, were suggested to improve the safety and health of the pool

\section{Acknowledgments}

The authors would like to gratitude the swimming pools personnel (Aran \& Bidgol city). And special thanks to the swimming pools management, technical engineers, and technical technicians who participated in this study.

\section{Ethical issues}

The authors certify that this manuscript is the original work of the authors, all data collected during the study are presented in this manuscript, and no data from the study has been or will be published separately.

\section{Competing interests}

The authors declare that they have no conflict of interests.

\section{Authors' contributions}

All authors contributed equally to the data collection, analysis, and interpretation. All authors critically reviewed, refined, and approved the manuscript.

\section{References}

1. Sohrabi P, Kashef M, Javadi pour M, Hoseini F. Investigation of location and accessibility of Urmia sport centers concerning national and international standards. Journal of Sport Management 2011; 3(10): 5-21. [In Persian].

2. Farsi A, Alizadeh M, Farsi S, Shojaei A. An investigation into safety conditions in Tehran universities and suggestion as to improving those condition. Research on Sport Science 2007; 5(15): 23-39. [In Persian].

3. Zangiabadi A, Aali R, Zarei A, Ghanbari R. Spatial analysis and health grading of swimming pools. Health System Research 2011; 6(4): 802-9. [In Persian].

4. Soltanin R, Salehzadeh k. Assessment of satisfaction of the health and safety of swimming in Tabriz city. Journal of Health Promotion Management 2015; 4(2): 48-56. [In Persian].

5. Glauner T, Waldmann P, Frimmel FH, Zwiener C. Swimming pool water-fractionation and genotoxicological characterization of organic constituents. Water Res 2005; 39(18): 4494-502. doi: 10.1016/j.watres.2005.09.005.

6. Shafiee S, Khalili Far M, Shabani S. Comparison of the health and safety of Guilan indoor pools with national and international standards. Biannual Journal of Sport Development and Management 2017; 5(2): 161-76. [In Persian].

7. Florentin A, Hautemanière A, Hartemann P. Health effects of disinfection by-products in chlorinated swimming pools. Int J Hyg Environ Health 2011; 214(6): 461-9. doi: 10.1016/j.ijheh.2011.07.012.

8. Williams CJ, Conrad D, Kothawala DN, Baulch HM. Selective removal of dissolved organic matter affects the production and speciation of disinfection byproducts. Sci Total Environ 2019; 652: 75-84. doi: 10.1016/j. scitotenv.2018.10.184.

9. Diana $M$, Felipe-Sotelo $M$, Bond T. Disinfection byproducts potentially responsible for the association between chlorinated drinking water and bladder cancer: a review. Water Res 2019; 162: 492-504. doi: 10.1016/j. watres.2019.07.014.

10. Kimura SY, Cuthbertson AA, Byer JD, Richardson SD. The DBP exposome: development of a new method to simultaneously quantify priority disinfection by-products and comprehensively identify unknowns. Water Res 2019; 148: 324-33. doi: 10.1016/j.watres.2018.10.057.

11. Omidvari M, Shahbazi D. Assessing and prioritizing health safety and environment risk in hospitals (Case study: Shahid Beheshti University of Medical Sciences). Journal of Ilam University of Medical Sciences 2016; 24(1): 43-54. [In Persian].

12. Baumer JH. Clinical risk management in neonatology. Semin Fetal Neonatal Med 2005; 10(1): 1. doi: 10.1016/j. siny.2004.09.011.

13. Arnetz JE, Zhdanova L, Arnetz BB. Patient involvement: a new source of stress in health care work? Health Commun 2016;31(12): 1566-72. doi: 10.1080/10410236.2015.1052872.

14. Ebrahimzadeh M, Halvani GH, Mortazavi M, Soltani R. Assessment of potential hazards by Failure Fodes and Fffect Analysis (FMEA) method in Shiraz oil refinery. Tibbi-i-kar 2011; 3(2): 16-23. [In Persian].

15. Berg AP, Fang TA, Tang HL. Variability of residual chlorine in swimming pool water and determination of chlorine consumption for maintaining hygienic safety of bathers with a simple mass balance model. J Water Health 2019; 17(2): 227-36. doi: 10.2166/wh.2018.217.

16. Ivor Norlin J. Public health investigation of swimming pool chlorine gas disinfection systems. Environmental Health Review 2019; 62(2): 53-8. doi: 10.5864/d2019-012.

17. Daraei A, Ziaeddinpour A, Taleb N, Sadeghzadeh A. Survey of water contamination and accidents occurring in swimming pools of Semnan in 2007 and 2008 and comparing the importance of these two parameters with each other based on Dolly index. 12th national conference environmental health; 2009 Nov 3-5; Tehran: Shahid Beheshti University of Medical Science; 2009.

18. Hon KL, Leung TF, Chan SY, Cheung KL, Ng PC. Indoor versus outdoor childhood submersion injury in a densely populated city. Acta Paediatr 2008; 97(9): 1261-4. doi: 10.1111/j.1651-2227.2008.00861.x.

19. Gouveia P, Felgueiras F, Mourão Z, Fernandes EDO, Moreira A, Gabriel MF. Predicting health risk from exposure to trihalomethanes in an Olympic-size indoor swimming pool among elite swimmers and coaches. 
J Toxicol Environ Health A 2019; 82(9): 577-90. doi: 10.1080/15287394.2019.1634383.

20. Haghmorad Korasti A, Nazari R, Zargar M. Study of microbial contamination of the public swimming pools with Escherichia coli and Pseudomonas aeruginosa and their physical parameters in Kermanshah, Iran. Qom University of Medical Sciences Journal 2016; 10(7): 65-73. [In Persian].

21. Abbasid Shahrivar P, Alizadeh SH. Identify and evaluate existing or potential risks throughout the product or service life of a service company using the Hazard Identification Method (HAZID). Petrochemical conference; 2008 Jul 28; Tehran.

22. Siddiqui DN, Nandan A, Sharma M, Srivastava A. Risk Management Techniques HAZOP \& HAZID Study. International journal on o ccupational Health \& Safety, Fire \& Environment-Allied Science. 2014;1(1):005-8.

23. Kim K, Kang H, Kim Y. Risk assessment for natural gas hydrate carriers: a hazard identification (HAZID) study. Energies 2015; 8(4): 3142-64. doi: 10.3390/en8043142.

24. Mohammadfam I, Mohseni S, Sohrabi MS, Hesami Arani M, Rezapour HA. Helping HSE team in learning from accident by using the management oversight and risk tree analysis method. Journal of Environmental Health and Sustainable Development 2016; 1(2): 91-9.

25. Hesami Arani M, Ghaneian MT, Halvani GH, Dakhilpour M, Delavar J, Rezapour HA, et al. Identification of hazardous and risk assessment of energy sources for Kavir Steel Complex using ETBA method in 2015. Journal of Basic Research in Medical Sciences 2017; 4(4): 18-27. doi: 10.29252/jbrms.4.4.1.

26. World Health Organization (WHO). Guidelines for Safe Recreational Water Environments - Volume 2: Swimming Pools and Similar Environments. Geneva: WHO; 2006.

27. Kim SJ, Seo JK, Ma KY, Park JS. Methodology for collision-frequency analysis of wind-turbine installation vessels. Ships Offshore Struct 2020: 1-17. doi: $10.1080 / 17445302.2020 .1735835$.

28. Rezapour H, Sohrabi M, Halvani G, Hesami Arani M. Investigation status of safety and intervention to promote it in workshops and laboratory of Isfahan University of Arts in 2014. Tibbi-i-kar 2017; 8(4): 18-26. [In Persian].

29. Barkhordari A, Shirazi J, Halvani GH. Identification of Hazardous and Risk Assessment of Tunneling Process Using JSA Method in the Dam \& Power plant site. The Journal of Toloo-e-Behdasht 2013; 11(3): 103-12. [In Persian].

30. Ehrampoush MH, Halvani GH, Ghaneian MT, Dehghani A, Hesami Arani M. Usage of William Fine, PHA methods for environmental risks management and estimation of control costs in the Kavir Steel Complex. Toloo-e-Behdasht 2016; 15(1): 10-25. [In Persian].

31. Nesticò A, He S, De Mare G, Benintendi R, Maselli G. The ALARP principle in the Cost-Benefit analysis for the acceptability of investment risk. Sustainability 2018; 10(12): 4668 .

32. Hesami Arani M, Ghaneian MT, Halvani GH, Dakhilpour M, Delavar J, Rezapour HA, et al. Identification of hazardous and risk assessment of energy sources for Kavir Steel Complex using ETBA method in 2015. Journal of Basic Research in Medical Sciences 2017; 4(4): 18-27. doi: 10.29252/jbrms.4.4.18.
33. Saleh F, Halvani G. Effect of engineering and nonengineering interventions on risk level of hazards, health and safety indicator in the Ceramics Industry. Tibbi-i-kar 2017; 9(2): 71-82. [In Persian].

34. Eshagh M, Sphere P: HAZID Techniques and Risk Assessment in Different Facilities of Mahmood Abad Oil Training Complex. 2016 Apr 19; 1ST National Conference Crisise, Health Safety, Environmentl, Mehr Arvand Instiute, Tehran; 2016.

35. Pasman HJ, Rogers WJ, Mannan MS. How can we improve process hazard identification? what can accident investigation methods contribute and what other recent developments? a brief historical survey and a sketch of how to advance. J Loss Prev Process Ind 2018; 55: 80-106. doi: 10.1016/j.jlp.2018.05.018.

36. Riyanto RD, Rasiman M. Developing the structural integrity management system for ageing fixed offshore oil platforms in Indonesia. Appl Mech Mater 2017; 862: 26570. doi: 10.4028/www.scientific.net/AMM.862.265.

37. Paltrinieri N, Tugnoli A, Buston J, Wardman M, Cozzani $\mathrm{V}$. Dynamic procedure for atypical scenarios identification (DYPASI): A new systematic HAZID tool. Journal of Loss Prevention in the Process Industries 2013; 26(4): 683-95.

38. McCoy SA, Wakeman SJ, Larkin FD, Jefferson ML, Chung PW, Rushton AG, et al. HAZID, a computer aid for hazard identification: 1. The STOPHAZ package and the HAZID code: an overview, the issues and the structure. Process Safety and Environmental Protection 1999; 77(6): 317-27. doi: 10.1205/095758299530242.

39. Moonis M, Wilday AJ, Wardman MJ. Semi-quantitative risk assessment of commercial scale supply chain of hydrogen fuel and implications for industry and society. Process Saf Environ Prot 2010; 88(2): 97-108. doi: 10.1016/j. psep.2009.11.006.

40. Halvani G, Ehrampoush MH, Ghaneian MT, Dehghani A, Hesami Arani M. Applying job hazard analysis and William Fine methods on risks identification and assessment of jobs in hot rolling steel, Iran. Journal of Mazandaran University of Medical Sciences 2017; 26(145): 293-303. [In Persian].

41. Nikaeen $M$, Hatamzadeh $M$, Vahid-Dastjerdi $M$, Hassanzadeh A, Mosavi Z, Rafiei M. An Investigation on physical, chemical and microbial quality of Isfahan swimming pool waters based on standard indicators. Journal of Isfahan Medical School 2010; 28(108): 346-56. [In Persian].

42. Ghaneian MT, Ehrampoush MH, Dad V, Amrollahi M, Dehvari M, Jamshidi B. An investigation on physicochemical and microbial water quality of swimming pools in Yazd. Journal of Shahid Sadoughi University of Medical Sciences 2012; 20(3): 340-49. [In Persian].

43. Hambly AC, Henderson RK, Storey MV, Baker A, Stuetz RM, Khan SJ. Fluorescence monitoring at a recycled water treatment plant and associated dual distribution system - implications for cross-connection detection. Water Res 2010; 44(18): 5323-33. doi: 10.1016/j.watres.2010.06.003.

44. Zazouli MA, Mahdavi Y, Moradi Golrokhi M, Balarak D. Investigation of water quality health indicators of the swimming pools in Urmia in 2013. Journal of Rafsanjan University of Medical Sciences 2015; 13(11): 1033-48. [In Persian]. 
45. Mehdinejad MH. The determination of quality of healthy indicators in swimming pools in Gorgan. Journal of Gorgan University of Medical Sciences 2003; 5(2): 89-95. [In Persian].

46. Detandt M, Nolard N. Dermatophytes and swimming pools: seasonal fluctuations. Mycoses 1988; 31(10): 495500 .

47. Moeinian K, Rastgoo T. Survey on six microbial quality indices inchlorinated swimming pools and Influence of pool depth and swimmers gender on it (case study). Koomesh 2016; 17(2): 426-32. [In Persian].

48. Jouzi SA, Kabzadeh S, Irankhahi M. Safety, Health \& Environmental risk assessment and management of Ahwaz
Pipe Manufacturing Company via "William Fine" method. Journal of Ilam University of Medical Sciences 2010; 18(1): 1-8. [In Persian].

49. White KM, Zhao X, Hyde MK, Hamilton K. Surviving the swim: psychosocial influences on pool owners' safety compliance and child supervision behaviours. Saf Sci 2018; 106: 176-83. doi: 10.1016/j.ssci.2018.03.020.

50. Seel RT, Macciocchi S, Velozo CA, Shari K, Thompson N, Heinemann AW, et al. The Safety Assessment Measure for persons with traumatic brain injury: item pool development and content validity. NeuroRehabilitation 2016; 39(3): 37187. doi: $10.3233 /$ nre-161369. 